\title{
Analisis Pengaruh Marketing Mix dan Citra Perguruan Tinggi Terhadap Kepuasan Mahasiswa STIMI Banjarmasin
}

\author{
Syamsuddinnor*. \\ STIMI Banjarmasin \\ Jl. Kuripan 26 Kel. Kuripan Kec. Banjarmasin Timur, Banjarmasin \\ *syams.stimi@gmail.com
}

\begin{abstract}
This study aims to empirically test and analyze the effect of Marketing Mix and College Image on Student Satisfaction at the Indonesian College of Management Sciences (STIMI) Banjarmasin. Research Methods, in accordance with the research objectives that have been formulated, this research uses an explanation pattern (level of explanation), namely research that intends to explain the position of the factors studied and the relationship between one factor and another. Thus, this study explains the effect of Marketing Mix and College Image on Student Satisfaction at the Indonesian College of Management Sciences (STIMI) Banjarmasin. The research sample is 148 respondents with the sampling technique using the Slovin formula and analyzed by Multiple Regression Analysis using the SPSS 25.0 for Windows program analysis tool. The results of the research are the independent variable (independent varable) Student Satisfaction (Y) While the dependent variable is the Marketing Mix as a variable (X1) with the indicators in this study: Product, Price, Place, Promotion, People, Physical, and Process. Image of Higher Education as a variable (X2) with indicators of Reputation, Tradition, and Higher Education Identity. Based on the results of the study, it partially had a significant effect on Student Satisfaction (Y) and the College Image variable (X2) partially had a significant effect on Student Satisfaction (Y) at the Indonesian College of Management Science (STIMI) Banjarmasin. Simultaneously Marketing Mix (X1) and College Image (X2) together have a significant effect on Student Satisfaction (Y) at the Indonesian College of Management Science (STIMI) Banjarmasin.
\end{abstract}

Keywords : Marketing Mix; Image of Higher Education; Student Satisfaction.

\begin{abstract}
Abstrak - Penelitian ini bertujuan untuk menguji secara empiris dan menganalisis pengaruh Marketing Mix dan Citra Perguruan Tinggi Terhadap Kepuasan Mahasiswa pada Sekolah Tinggi Ilmu Manajemen Indonesia (STIMI) Banjarmasin. Metode Penelitian, sesuai dengan tujuan penelitian yang telah dirumuskan, maka penelitian ini menggunakan pola eksplanasi (level of explanation) yaitu penelitian yang bermaksud menjelaskan kedudukan faktor-faktor yang diteliti serta hubungan antara satu faktor dengan faktor yang lain. Dengan demikian penelitian ini menjelaskan pengaruh Marketing Mix dan Citra Perguruan Tinggi terhadap Kepuasan Mahasiswa Sekolah Tinggi Ilmu Manajemen Indonesia (STIMI) Banjarmasin. Sampel penelitian yaitu 148 responden dengan teknik pengambilan sampel menggunakan rumus Slovin dan dianalsis dengan Analisis Regresi Berganda dengan menggunakan alat bantu analisis program SPSS 25.0 for Windows. Hasil Penelitian variabel Variabel Bebas (independet varable) Kepuasan Mahasiswa (Y) Sedangkan variabel dependen adalah Marketing Mix sebagai variabel (X1) dengan indikator dalam penelitian ini adalah : Product, Price, Place, Promotion, People, Physical, dan Process. Citra Perguruan Tinggi sebagai variabel (X2) dengan indikator Reputasi, Tradisi, dan Identitas Perguruan Tinggi. Berdasarkan hasil penelitian secara parsial berpengaruh signifikan terhadap Kepuasan Mahasiswa (Y) dan variabel Citra Perguruan Tinggi (X2) secara parsial berpengaruh signifikan terhadap Kepuasan Mahasiswa (Y) pada Sekolah Tinggi Ilmu Manajemen Indonesia (STIMI) Banjarmasin. Secara simultan Marketing Mix (X1) dan Citra Perguruan Tinggi (X2) secara bersama-sama berpengaruh signifikan terhadap Kepuasan Mahasiswa (Y) pada Sekolah Tinggi Ilmu Manajemen Indonesia (STIMI) Banjarmasin.
\end{abstract}

Kata Kunci : Marketing Mix; Citra Perguruan Tinggi; Kepuasan Mahasiswa.

\section{PENDAHULUAN}

Perguruan tinggi memiliki peran utama sebagai sarana untuk mencapai tujuan dari pelaksanaan program pendidikan. Oleh sebab itu, pemberdayaan perguruan tinggi sebagai unit pendidikan dapat secara langsung mengelola peserta didik dengan efektif dan efisien[1]. Hal ini terkait dengan persaingan era global yang sangat kompetitif, maka semakin besar dan beragam adanya tuntutan untuk pemenuhan kebutuhan Ilmu Pengetahuan dan Teknologi (IPTEK) dan juga usaha untuk meningkatkan status sosial di masyarakat[2]. Semakin banyak berdiri perguruan tinggi swasta (PTS) baru dan program studi baru akan memunculkan persaingan antar perguruan tinggi. Maka, dengan demikian pihak perguruan tinggi perlu mengantisipasi adanya tantangan yang dihadapi terkait dengan persaingan yaitu bagaimana pengelolaan perguruan tinggi, proses belajar mengajar dan pendidikan nilai. Kemudian tantangan lain yang harus dipikirkan oleh perguruan tinggi adalah mengenai struktur institusi dan kebiasan cara berpikir yaitu misalnya yang berkaitan dengan akreditasi, hak intelektual dan perguruan tinggi sbagai suatu komunitas[3]-[5]. Permasalahan yang terjadi pada saat 
sekarang ini adalah tentang kesiapan suatu perguruan tinggi dalam menemukan strategi untuk memperebutkan calon mahasiswa baru dengan jumlah sama besar bahkan mungkin lebih besar dari tahun sebelumnya, agar perguruan tinggi swasta dapat melaksanakan aktivitas secara operasional. Perkembangan perguruan tinggi swasta dan perkembangan jumlah mahasiswa berdampak pada semakin ketatnya persaingan antar perguruan tinggi swasta[6]. Daya saing suatu perguruan tinggi juga ditentukan oleh mutu perguruan tinggi yang bersangkutan. Jasa pendidikan tinggi di Indonesia juga dilakukan penilaian terhadap semua aktivitas yang dilaksanakan apakah sesuai standar yang saat ini dipercayakan pada hasil penilaian dari Badan Akreditasi Nasional Perguruan Tinggi (BAN-PT) yang sebenarnya sebagai titik sentral dalam pengelolaan jasa pendidikan tinggi. Oleh karena itu, khusus bagi pengelola PTS supaya memperoleh adanya umpan balik terkait kualtias jasa yang diberika sesuai dengan penilaian, pengelolaan perguruan tinggi swasta yang ideal bermuara pada pemuasan kebutuhan mahasiswa sebagai pelanggan (total customers satisfaction)[7].

Adanya perubahan yang terjadi dalam lingkungan bisnis memacu peningkatan intensitas persaingan antar perguruan tinggi, sehingga setiap penyedia jasa pendidikan tinggi selalu berusaha menawarkan jasa sesuai dengan yang diinginkan oleh mahasiswa. Di samping bersaing dengan dengan perguruan tinggi negeri (PTN) seluruh PTS juga dihadapkan pada persaingan dengan sesame PTS yang bisa memunculkan keterpurukan PTS karena tidak mampu bersaing. Oleh sebab itu, beban dari PTS untuk selalu eksis semakin berat karena jumlah pesaing semakin bertambah, terutama pesang perguruantinggi negeri yang membuka program pendidikan khusus (program ekstensi) hal ini akan mempengaruhi minat calon mahasiswa dari perguruan tinggi swasta, walaupun penyeberan jumlah mahasiswa tetap lebih besar dibandingkan perguruan tinggi negeri. Siatuasi yang dihadapi oleh perguruan tinggi saat ini adalah disamping bersaing untuk menjaring calon-calon mahasiswa baru, juga yang penting adalah bagaimana mengelola para mahasiswa yang masih aktif agar tetap terus melanjutkan proses pendidikan dan tidak terjadi droup out dengan alasan yang muncul hanya karena pelayanan yang kurang memuaskan. Bisnis pendidikan juga merupakan bisnis jasa, oleh sebab itu hal utama yang dipegang adalah membangun dan menjaga kepercayaan konsumen atau masyarakat serta pada akhirnya merasakan puas.
Dalam jasa pendidikan tinggi kepuasan mahasiswa juga ditentukan terkait dengan para mahasiswa yang menerima pelayanan perkuliahan serta yang diperoleh. Apabila mahasiswa memperoleh kepuasan akan memberikan rekomendasi yang positif tentang perguruan tinggi sebagai tempat belajar. Selain itu juga mahasiswa tidak akan pindah ke perguruan tinggi lain, bahkan bersedia menarik calon mahasiswa untuk kuliah ke perguruan tinggi tersebut. Dengan demikian, perguruan tinggi swasta harus dipandang sebagai suatu usaha atau perusahaan jasa pendidikan. Dimana, perusahaan jasa pendidikan tidak hanya semata-mata hanya mencari keuntungan saja, namun juga harus berusaha keras untuk memuaskan mahasiswa, sehingga diharapkan mahasiswa bersedia terus-menerus melakukan daftar ulang/heregistrasi pada setiap semester sampai dengan lulus menyelesaikan studi.

Adapun cara untuk mencapai dan mempertahankan keunggulan kompetitif adalah dengan cara pemanfaatan unsur-unsur bauran pemasaran. Pemasaran industri manufaktur, untuk marketing mix terdiri atas: Product, price, place dan promotion, yang bisa disingkat dengan 4P. Namun untuk sektor industri jasa, marketing mix telah berkembang sesuai dengan karakteristik jasa, sehingga menjadi 7P, yaitu dengan penambahan $3 \mathrm{P}$ berupa process, people, dan physical evidence [28]. Hal tersebut berdasarkan pendapat yang dikemukakan Zeithaml dan Bitner bahwa elemen marketing mix terdiri atas : product, price, place, promotion, people, physical evidence, dan process. Bauran pemasaran yang efektif di perguruan tinggi diharapkan mampu memenuhi kebutuhan dan keinginan dari para mahasiswa. Produk, harga, promosi, saluran distribusi/tempat layanan jasa, orang, bukti fisik, dan proses merupakan suatu faktor yang dapat dimungkinkan mampu mempengaruhi kepuasan dari para mahasiswa, sebagai gambaran seperti ketersediaan variasi pilihan produk yang lengkap, status akreditasi, biaya pendidikan, promosi yang tepat sasaran, tempat yang strategis, tenaga pendidik yang profesional, kondisi kampus yang kondusif dan sistem manajemen yang baik tentu akan menciptakan kepuasan terhadap mahasiswa. Citra sebuah perguruan tinggi dapat dinilai dari seperangkat komponen. Komponen citra meliputi kompetensi dosen, mutu lulusan, daya dukung sarana dan prasarana. Selain itu, dinilai pula dari jejaring kerja sama atau program university social esponsibility atau tanggung jawab sosial perguruan tinggi yang meneyentuh kebutuhan masyarakat. Bauran pemasaran jasa dan citra yang 
dirasakan juga dibandingkan dengan yang diharapkan oleh mahasiswa, apabila mendekati harapan mahasiswa, maka akan menimbulkan kepasan bagi mahasiswa. Dengan kata lain, apabila bauran pemasaran jasa dan citra perguruan tinggi, semakin baik kinerjanya dan diterima oleh para mahasiswa, maka akan semakin tinggi pula tingkat kepuasan mahasiswa terhadap perguruan tinggi.

Kegiatan penerimaan mahasiswa baru (PMB) di STIMI Banjarmasin dalam setiap tahunnya yang mendaftar terdapat penurunan dalam setiap periode penerimaannya, yang mana hal ini disebabkan berbagai masalah terutama faktor internal dan eksternal dimana sekarang ini Perguruan Tinggi dituntut untuk lebih aktif, Inovatif, dan kreatif lagi dalam mengelola semua elemen yang ada dalam lembaga, supaya kita bisa bersaing dalam merekrut calon mahasiswa yang saat ini mereka dihadapkan banyak pilihan tempat kuliah, sehingga secara tidak langsung akan mempengaruhi jumlah penerimaan mahasiswa baru[4]. STIMI Banjarmasin salah satu PTS yang masih eksis di Kota Banjarmasin juga mengetahui seberapa besar pengaruh faktor bauran pemasaran dan citra perguruan tinggi terhadap kepuasan mahasiswa. Oleh karena itu, masalah utama dalam penelitian ini yaitu tentang pengaruh bauran pemasara jasa dan citra perguruan tinggi terhadap kepuasan mahasiswa pada Sekolah Tinggi Ilmu Manajemen Indonesia (STIMI) Banjarmasin. Kepuasan mahasiswa merupakan penilaian yang diberikan atas perbedaan antara harapan mahasiswa dengan kinerja atau hasil (kenyataan) yang dirasakan oleh mahasiswa atas pelayanan yang diberikan oleh perguruan tinggi. Kepuasan mahasiswa akan memberikan manfaat bagi perguruan tinggi. Mahasiswa yang puas akan menggunakan jasa perguruan tinggi tersebut dengan studi lanjut pada perguruan tinggi yang sama. Selain itu dia juga akan mempromosikan layanan yang baik dariperguruan tinggi kepada calon mahasiswa yang lain sehingga akan meningkatkan jumlah mahasiswa yang kuliah diperguruan tinggi tersebut. Kepuasan mahasiswa dalam penelitian ini adalah kesesuaian antar harapan dan kinerja dari layanan akademik dan birokrasi yang diterima oleh mahasiswa.

\section{KAJIAN PUSTAKA}

\section{Pemasaran Jasa Pendidikan}

Menentukan kebutuhan, keinginan, clan harapan dari para pemangku kepentingan perguruan tinggi atau pelanggan jasa pendidikan, merupakan bagian penting dari strategi pemasaran jasa pendidikan.

Adapun beberapa tujuan dari pemasaran pendidikan adalah (1) memberi informasi kepada masyarakat tentang produk-produk lembaga pendidikan, (2) meningkatkan minat dan ketertarikan masyarakat path produk lembaga pendidikan, (3) membedakan produk lembaga pendidikan dengan lembaga pendidikan lain, (4) memberikan penilaian lebih path masyarakat dengan produk yang ditawarkan, dan (5) menstabilkan eksistensi dan kebermaknaan lembaga pendidikan di masyarakat[1]. Jadi, yang ingin dicapai dari pemasaran pendidikan adalah mendapatkan pelanggan yang disesuaikan dengan target, baik itu yang berkaitan dengan kualitas maupun kuantitas dari calon pelanggan. Terdapat lima tahap penting dalam menerapkan pemasaran jasa pendidikan, yaitu: (a) mengidentifikasi kebutuhan atau masalah pemasaran jasa pendidikan; (b) melakukan riset atau audit pemasaran jasa pendidikan; (c) melakukan perencanaan pemasaran jasa pendidikan; (d) menentukan bauran pemasaran (marketing mix) jasa pendidikan; dan (e) menentukan strategi dan taktik pemasaran jasa pendidikan[2].

\section{Bauran Pemasaran Jasa(marketing mix)}

Bauran pemasaran (marketing mix) merupakan unsur atau elemen internal penting yang membentuk program pemasaran sebuah organisasi. Bauran pemasaran merupakan salah satu konsep universal yang telah dikembangkan dalam pemasaran[2]. Dalam hal ini berarti bauran pemasaran jasa adalah elemenelemen organisasi perusahaan yang dapat dikontrol oleh perusahaan dalam melakukan komunikasi dengan konsumen dan akan dipakai untuk memnaskan konsumen. Dalam pemasaran industri manufaktur, marketing mix tradisional (4P) telah banyak membawa kesuksesan perusahaan untuk mencapai tujuan, tetapi dalam industri jasa marketing mix (4P) telah dimodifikasi dan dikembangkan menjadi 7P yakni : product, price, place, promotion, people, physical evidence, dan process [28]

\section{Citra Perguruan Tinggin}

Citra perusahaan yang baik akan terbentuk dengan sendirinya di benak pelanggan. Citra terjadi berdasarkan sesuatu yang telah diterima pelanggan dari perusahaan. Untuk itu, seharusnya perusahaan 
harus selalu berupaya membentuk citra positif di benak pelanggan[16]. Dengan adanya citra positif akan menjadikan perusahaan mendapat keuntungan yang tidak temilai baik itu berupa: (1) penghargaan dari pihak terkait, (2) bertahannya pdanggan untuk menggunakan produk jasn yang dihasilkan, dan (3) akan memunculkan pelanggan-pelanggan baru. Ataman dan Burc mengatakan bahwa citra itu sebagai anti yang diberikan oleh masyarakat. Apabila masyarakat mengartikan suatu organisasi memiliki citra yang baik atau berkesan, maka pelanggan akan berbondong-bondong untuk mendatangi organisasi tersebut[20]. citra perusahaan adalah hasil dari interaksi keyakinan seseorang, ide, perasaan, dan kesan tentang perusahaan. Citra perguruan tinggi adalah pendapat responden berupa gambaran dan kesan umum akan suatu perguruan tinggi dengan melihat berbagai aspek yang membentuk citra dengan memproses informasi dari berbagai sumber setiap waktu yang diperoleh oleh perguruan tinggi[1].

\section{Kepuasan Mahasiswa}

Kepuasan pelanggan telah menjadi konsep sentral dalam teori dan praktik pemasaran, serta merupakan salah satu tujuan esensial bagi aktivitas bisnis [24], Kepuasan pelanggan berkontribusi pada sejumlah aspek krusial, seperti terciptanya loyalitas pelanggan, meningkatnya reputasi perusahaan, berkurangnya elastisitas harga, berkurangnya biaya transaksi masa depan, dan meningkatnya efisiensi dan produktivitas karyawan[21]. Kepuasan mahasiswa adalah sikap positif mahasiswa terhadap pelayanan lembaga pendidikan tinggi karena adanya kesesuaian antara harapan dari pelayanan dibandingkan dengan kenyataan yang diterimanya [22].

\section{METODE PENELITIAN}

Penelitian ini dengan pendekatan eksploratori yaitu riset pemasaran yang dimaksudkan untuk mengembangkan dan mengumpulkan semua data prakiraan dan opini-opini untuk member arah bagi penelitian selanjutnya [14]. Untuk menganalisa vairabel bauran pemasaran jasa (X1), Citra Perguruan Tinggi (X2) dan Kepuasan Mahasiswa (Y) pada Sekolah Tinggi Ilmu Manajemen Indonesia (STIMI) Banjarmasin [23]-[24].

Dengan menggunakan Purposive Judgement yang menjadi populasi dalam penelitian ini adalah seluruh mahasiswa Strata 1 (S1) Sekolah Tinggi Ilmu
Manajemen Indonesia (STIMI Banjarmasin) dari Angkatan/ tahun masuk 2019 (semester I), 2018 (semester III), 2017 (semeter V), dan 2016 (semester VII). Jumlah populasi 316 orang mahasiswa[5].

Sampel adalah sebagian dari populasi, terdiri atas sejumlah anggota orang dipilih terdiri dari populasi karena populasi dalam penelitian ini menurut penulis terlalu banyak, maka untuk mempermudah pelaksanaan penelitian, faktor waktu, biaya dan dianggap bisa mewakili populasi perlu untuk menentukan sampel, jumlah sampel yang diambil pada penelitian ini adalah sebanyak mahasiswa (i) sebanyak 148 orang[5]. Untuk menentukan jumlah sampel digunakan rumus Slovin dengan tingkat kesalahan 5\% seperti dibawah ini:
Dimana ; $\quad \mathrm{n}=$ jumlah sampel
$\mathrm{N}=$ Jumlah populasi
$\mathrm{e}=$ persentase $(\%)$ kelonggaran
Ketidaktelitian karena kesalahan pengambilan sampel yang masih dapat ditolerir.

Sehubungan dengan metode yang akan digunakan dalam penelitian ini adalah metoda deskriptif, maka ukuran minimal tingkat presisi (e) yang ditetapkan adalah dapat $5 \%$ dari populasi.

Berdasarkan rumus diatas, maka jumlah sampel (n) dalam penelitian ini adalah: $\mathrm{n}=147.83=148$ orang responden.

Penelitian ini bertujuan menguji dan menganalisis hubungan kausal antara variabel bebas dan variabel terikat, sekaligus memeriksa validitas dan reliabilitas instrument penelitian secara keseluruhan. Oleh karena itu digunakan teknik analisis Regresi linear berganda menggunakan software SPSS versi 25.0[5].

Model analisis Regresi Linear Berganda yang digunakan Hair, et al. (2010) adalah sebagai berikut:

$$
\mathbf{Y}=\alpha+\beta \mathbf{X} 1+\boldsymbol{\beta} \mathbf{2} 2+\mathbf{e i}
$$

Keterangan :

$$
\begin{array}{ll}
\mathrm{Y} & =\text { Kepuasan Mahasiswa } \\
\mathrm{X} 1 & =\text { Bauran Pemasaran Jasa } \\
\mathrm{X} 2 & =\text { Citra Perguruan Tinggi } \\
\alpha & =\text { Konstanta } \\
\beta & =\text { Koefesien } \\
\mathrm{ei} & =\text { Error Term }
\end{array}
$$

Teknik pengumpulan data yang dipakai dalam penelitian ini ada beberapa cara, yaitu :

1. Observasi, yaitu penelitian yang dilakukan dengan mendatangi kampus, dalam hal ini adalah Mahasiswa (i) Strata 1 (S1) STIMI Banjarmasin. 
Jenis observasi yang penulis gunakan adalah observasi terpimpin.

2. Teknik kuesioner yang penulis gunakan adalah angket atau kuesioner dengan menggunakan skala ordinal 5 (lima), nilai yang diperoleh merupakan indikator untuk pasangan variabel bebas (independen) $\mathrm{X}$ dan variabel tetap (dependen) Y[19]. Dan variabel yang diteliti menggunakan analisis Likert pada tabel berikut:

Tabel 1 Skala Likert

\begin{tabular}{lcc}
\hline No & Pertanyaan/pernyataan & Jawaban \\
\hline $\mathbf{1}$ & Sangat Setuju (SS) & $\mathbf{5}$ \\
$\mathbf{2}$ & Setuju (S) & $\mathbf{4}$ \\
$\mathbf{3}$ & Kurang Setuju (KS) & $\mathbf{3}$ \\
$\mathbf{4}$ & Tidak Setuju (TS) & $\mathbf{2}$ \\
$\mathbf{5}$ & Sangat Tidak Setuju (STS) & 1 \\
\hline
\end{tabular}

3. Dokumentasi, yaitu penulis mempelajari dokumen-dokumen yang ada pada Bagian BAAK STIMI Banjarmasin untuk dijadikan sumber data sebagai bahan pengelolaan data berikutnya.

\section{HASIL DAN PEMBAHASAN}

\section{Hasil Analisis Data}

Pengujian hipotesis dilakukan untuk menguji hipotesis yang diajukan. Hipotesis yang diajukan dalam penelitian ini terkait variabel Bauran Pemasaran Jasa dan Citra Perguruan Tinggi terhadap Kepuasan Mahasiswa pada Sekolah Tinggi Ilmu Manajemen Indonesia (STIMI) Banjarmasin. Analisis regresi berganda dipilih untuk menganalisis pengajuan hipotesis dalam penelitian ini. Analisis regresi digunakan untuk mengukur kekuatan hubungan antara dua variabel atau lebih, juga menunjukan arah hubungan antara variabel dependen dengan independen. Analisis regresi linier berganda adalah hubungan secara linier antara dua atau lebih variable independen $(\mathrm{X})$ dengan dengan variabel dependen (Y)[5]. Analisis ini untuk memprediksi nilai dari variabel dependen apabila nilai variabel independen mengalami kenaikan atau penurunan dan untuk mengetahui arah hubungan, antara variabel independen dengan variabel dependen apakah masingmasing variabel independen berhubungan positif atau negatif. Berikut ini hasil analisis regresi berganda yang dilakukan dengan menggunakan program SPSS 25[5].

\section{Uji F (Simultan)}

Uji $F$ dilakukan untuk menguji signifikansi koefisien regresi seluruh prediktor (varibel independen) di dalam model secara serentak (simultan)[5]. Jadi menguji signifikansi pengaruh Bauran Pemasaran Jasa dan Citra Perguruan Tinggi terhadap Kepuasan Mahasiswa. Rumusan hipotesis nol (H0) dan hipotesis alternatif (Ha) mengenai pengaruh variabel bauran pemasaran jasa dan citra perguruan tinggi terhadap kepuasan mahasiswa sebagai berikut:

H0 : tidak ada pengaruh Bauran Pemasaran Jasa dan Citra Perguruan Tinggi terhadap Kepuasan Mahasiswa pada Sekolah Tinggi Ilmu Manajemen Indonesia (STIMI) Banjarmasin.

Ha : ada pengaruh pengaruh Bauran Pemasaran Jasa dan Citra Perguruan Tinggi terhadap Kepuasan Mahasiswa pada Sekolah Tinggin Ilmu Manajemen Indonesia (STIMI) Banjarmasin.

Kriteria pengambilan keputusan adalah sebagai berikut :

1. diterima jika Fhitung $\leq$ Ftabel pada $\alpha=5 \%$

2. diterima jika Fhitung > Ftabel pada $\alpha=5 \%$

Untuk menentukan nilai $\mathrm{F}$ maka diperlukan adanya derajat bebas pembilang dan derajat bebas penyebut, dengan rumus sebagai berikut:

$\mathrm{df}($ Pembilang $)=\mathrm{k}-1$

df (Penyebut) $=\mathrm{n}-\mathrm{k}$

Keterangan:

$\mathrm{n}=$ jumlah sampel penelitian

$\mathrm{k}=$ jumlah variabel bebas dan terikat

Pada penelitian ini diketahui jumlah sampel (n) 38 dan jumlah keseluruhan variabel (k) adalah 3 , sehingga diperoleh:

$\mathrm{df}$ (pembilang $)=3-1=2$

df (penyebut) $=148-3=145$

Maka diperoleh nilai Ftabel maka diperoleh nilai sebesar 3.06 dan Nilai Fhitung akan diperoleh dengan menggunakan bantuan SPSS, kemudian akan dibandingkan dengan Ftabel pada tingkat $\alpha=5 \%$.

\begin{tabular}{|c|c|c|c|c|c|c|}
\hline \multicolumn{7}{|c|}{ ANOVA $^{a}$} \\
\hline \multicolumn{2}{|c|}{ Model } & \multirow{2}{*}{$\begin{array}{r}\text { Sum of Squares } \\
1741.302\end{array}$} & \multirow{2}{*}{ df } & \multirow{2}{*}{$\begin{array}{r}\text { Mean Square } \\
870.651\end{array}$} & \multirow{2}{*}{$\begin{array}{c}\mathrm{F} \\
136.442\end{array}$} & \multirow{2}{*}{$\begin{array}{l}\text { Sig. } \\
.000^{b}\end{array}$} \\
\hline 1 & Regression & & & & & \\
\hline & Residual & 925.258 & 145 & 6.381 & & \\
\hline & Total & 2666.561 & 147 & & & \\
\hline
\end{tabular}

a. Dependent Variable: $Y$

b. Predictors: (Constant), X2, X1

Sumber : Data hasil output SPSS 25, 2021

Gambar 1. Hasil Analisis Regresi Linear Berganda 


\section{Uji t (Parsial)}

Berdasarkan perhitungan statistik dengan menggunakan program SPSS 25 yang termuat dalam gambar 1 di bawah ini:

\begin{tabular}{|c|c|c|c|c|c|c|}
\hline \multicolumn{7}{|c|}{ Coefficients $^{\mathbf{a}}$} \\
\hline \multirow{2}{*}{\multicolumn{2}{|c|}{ Model }} & \multicolumn{2}{|c|}{$\begin{array}{l}\text { Unstandardized } \\
\text { Coefficients }\end{array}$} & $\begin{array}{l}\text { Standardized } \\
\text { Coefficients }\end{array}$ & \multirow[b]{2}{*}{$\mathrm{t}$} & \multirow[b]{2}{*}{ Sig. } \\
\hline & & $\mathrm{B}$ & Std. Error & Beta & & \\
\hline \multirow[t]{3}{*}{1} & (Constant) & 2.127 & 1.930 & & 1.102 & .272 \\
\hline & $\mathrm{X} 1$ & .135 & .033 & .362 & 4.137 & .000 \\
\hline & $\mathrm{X} 2$ & .313 & .057 & .482 & 5.509 & .000 \\
\hline
\end{tabular}

Sumber : Data output SPSS 25, 2020

Gambar 2. Hasil Uji t

Berdasarkan Gambar 2 dengan perhitungan statistik menggunakan menggunakan program SPSS 25 di peroleh hasil Bauran Pemasaran Jasa (X1) nilai $t_{\text {hitung }}(4.137)>t_{\text {tabel }}(1.655)$, maka HO ditolak (Ha diterima), Bauran Pemasaran Jasa (X1) berpengaruh positif terhadap Kepuasan Mahasiswa dengan tingkat signifikansi 0.000 . Artinya semakin tinggi Bauran Pemasaran Jasa semakin tinggi Kepuasan Mahasiswa dan sebaliknya. Citra Perguruan Tinggi (X2) nilai thitung (5.509) $>t_{\text {tabel }}$ (1.655), maka H0 ditolak (Ha diterima), Citra Perguruan Tinggi berpengaruh positif terhadap kinerja karyawan dengan tingkat signifikansi 0.000. Artinya semakin tinggi Citra Perguruan Tinggi semakin tinggi Kepuasan Mahasiswa dan sebaliknya. Hasil ini sejalan dengan hasil penelitian lainnya bahwa yang mengemukakan bahwa Bauran Pemasaran Jasa dan Kualitas Layanan secara simultan berpengaruh signifikan terhadap Kepuasan Mahasiswa dengan besaran pengaruh Sekolah Tinggi [15].

\section{Implikasi Hasil Penelitian}

Dari hasil yang dilakukan oleh peneliti yang diperoleh melalui uji secara statistik menunjukan bahwa variabel bauran pemasaran jasa dan citra perguruan tinggi terhadap kepuasan mahasiswa pada Sekolah Tinggi Ilmu Manajemen Indonesia (STIMI) Banjarmasin membuktikan bahwa variabel Bauran Pemasaran Jasa dan Citra Perguruan Tinggi secara simultan terhadap Kepuasan Mahasiswa pada Sekolah Tinggi Ilmu Manajemen Indonesia (STIMI) Banjarmasin. Jika bauran pemasaran jasa semakin baik, maka kepuasan rnahasiswa Sekolah Tinggi Ilmu Manajemen Indonesia (STIMI) Banjarmasin akan semakin meningkat. Peran bauran pemasaran jasa dalam meningkatkan kepuasan mahasiswa, tidak terlepas dari product, price, place, promotion, people, physical evidence, dan process. Dalam industri jasa marketing mix (4P) telah dimodifikasi dan dikembangkan menjadi 7P yakni : product, price, place, promotion, people, physical evidence, dan process. Faktor tradisi, ideologi, nama perusahaan. reputasi, tingkat harga, berbagai layanan, dan kualitas yang dikomunikasikan setiap kepada orang yang berinteraksi dengan perusahaan jasa untuk membentuk citra[28].

Hasil penelitian bauran pemasaran jasa pada Sekolah Tinggi Ilmu Manajemen Indonesia (STIMI) Banjarmasin sangat dipengaruhi oleh price dan citra sangat dipengaruhi oleh indikator reputasi. Apabila kedua indikator tersebut dipersepsikan baik oleh mahasiswa, rnaka hal ini merupakan indikasi bahwa STIMI Banjarmasin mampu memenuhi kebutuhan dan keinginan atau dapat dinyatakan telah memberikan rasa puas pada mahasiswa. Pada variabel kepuasan mahasiswa kontribusi terbesar berasal dari keinginan merekomendasi kembali. Dengan demikian, mahasiswa akan merekomendasi pada pihak lain ketika price dan reputasi Perguruan Tinggi baik.

Berdasarkan hasil uji koefisien regresi pengaruh antar variabel pada model akhir, menunjukkan bahwa variabel bauran pemasaran jasa memiliki pengaruh lebih besar daripada citra. Namun demikian, bauran pemasaran jasa dan citra yang dirasakan dibandingkan dengan yang diharapkan, apabila mendekati harapan mahasiswa, maka akan terjadi kepuasan mahasiswa. Dengan kata lain, apabila bauran pemasaran jasa dan citra semakin baik kinerjanya dan diterima mahasiswa, maka akan semakin tinggi tingkat kepuasan yang dirasakan mahasiswa. Di samping itu, bauran pemasaran dan citra yang digambarkan pada kepuasan mahasiswa dapat di winakan sebagai kekuatan perguruan tinggi. Mengingat, citra berkontribusi lemah terhadap kepuasan, maka STIMI Banjarmasin perlu merumuskan strategi yang tepat untuk membangun citra yang baik berdasarkan pandangan internal maupun eksternal kampus.

\section{Kesimpulan}

\section{KESIMPULAN DAN SARAN}

Berdasarkan hasil pegolahan dan analisis data mengenai pengaruh marketing mix dan citra perguruan tinggi terhadap kepuasan mahasiswa pada Sekolah Tinggi Ilmu Manajemen Indonesia (STIMI) Banjarmasin dapat ditarik kesimpulan dari hasil perhitungan statistik bahwa variabel kepuasan mahasiswa dapat dijelaskan secara signifikasi berpengaruh oleh marketing mix dan citra perguruan tinggi. Jadi dapat disimpulkan bahwa variabel 
marketing mix dan citra perguruan tinggi secara simultan berpengaruh signifikansi terhadap kepuasan mahasiswa pada Sekolah Tinggi Ilmu Manajemen Indonesia (STIMI) Banjarmasin. Item penilaian tertinggi oleh responden pada variabel bauran pemasaran jasa yaitu place yang menyatakan bahwa lokasi kampus STIMI Banjarmasin letaknya strategis dan dekat dengan fasilitas umum ini berarti untuk lokasi kampus dinilai oleh responden sangat baik sedangkan penilaian terendah oleh respoden yaitu pada item price jumlah nominal biaya perkuliahan ini berarti untuk jumlah nomimal biaya perkuliahan STIMI Banjarmasin dinilai oleh responden masih kurang baik. Item penilaian tertinggi oleh responden pada variabel citra perguruan tinggi yaitu elemen reputtasi yang menyatakan bahwa STIMI Banjarmasin berprestasi dalam melaksanakan good university governance, berhak mendapatkan penghargaan, dan mengalami perkembangan dalam aspek kualitas ini berarti pada reputasi perguruan tinggi STIMI Banjarmasin dinilai repsonden sangat baik sedangkan penilaian terendah oleh respoden yaitu pada elemen tradisi yaitu pada kegiatan pengenalan kampus, keaktifan dalam kegiatan ilmiah baik didalam maupun luar kampus, dan pada peringatan hari-hari besar dinilai oleh responden masih kurang baik.

\section{Saran}

Berdasarkan hasil temuan-temuan penelitian yang diperoleh, maka penulis mengajukan beberapa saran terkait hasil penelitian yang telah dilaksanakan, khususnya bagi pihak STIMI Banjarmasin, umumnya bagi seluruh perguruan tinggi yang menggunakan bauran pemasaran jasa perguruan tinggi yakni dalam rangka membentuk citra perguruan tinggi serta meningkatkan intensitas calon mahasiswa untuk masuk ke perguruan tinggi. Adapun saran yang berikan yaitu dampak positif yang ditimbulkan oleh penggunaan bauran pemasaran jasa perguruan tinggi yakni elemen-elemennya terhadap intensi calon mahasiswa dimana perlu ditindak lanjut dengan adanya peningkatan dalam hal penawaran jasa pendidikan di perguruan tinggi terhadap calon mahasiswa dengan memberikan berbagai hal baru. Pihak panitia penerimaan mahasiswa baru juga harus mampu memaparkan nilai lebih dari produk pendidikan STIMI Banjarmasin yang dipromosikannya berupa jasa pendidikan agar calon mahasiswa cenderung tertarik bergabung dengan STIMI Banjarmasin dan dengan intensitas yang tinggi agar calon mahasiswa mampu mengenal STIMI Banjarmasin dan menjadikannya sebagai skala prioritas untuk pemilihan PTS untuk melanjutkan pendidikan selanjutnya. Dan yang tak kalah pentingnya, dalam pemilihan strategi bauran pemasaran jasa perguruan tinggi yang dipilih dan dilakukan oleh STIMI Banjarmasin, pihak panitia penerimaan mahasiswa hendaknya memperhatikan data dan informasi yang relevan supaya bauran pemasaran yang dipilih dan akan dilaksanakan menjadi pemasaran yang efektif bagi menarik minat mahasiswa untuk masuk ke STIMI Banjarmasin.

\section{REFERENSI}

[1] Alma, Buchari dan R. Hurriyati. 2005. Management Corporate dan Strategi Pemasaran Jasa Pendidikan. Bandung: Alfabeta

[2] Alma, Buchari. 2009. Manajemen Pemasaran don Pemasaran Jasa. Bandung : Alfabeta.

[3] Blithe, J. 2006. Principles and Practices of Marketing. London: Thomson Learning.

[4] Djojodibroto, Darmanto.2004. Tradisi kehidupan Akadernik. Gal an g Press: Yogyakarta

[5] Ghozali, Imam. 2005. Aplikasi Analisis Multivariate dengan Program SPSS. Semarang: Badan Penerbit Universitas Diponegoro.

[6] Gultom, Dedek K. 2014. Pengaruh Bauran Pemasaran Jasa dan Kualitas Pelayanan Terhadap Kepuasan Mahasiswa Program Studi Manajemen Fakultas Ekonomi Universitas Muhammadiyah Sumatera Utara. Jurnal Manajemen \& Bisnis Vol 14 No. 01 April 2014

[7] Husain, Umar. 2005. Manajemen Riset dan Perilaku Konsumen. PT. Gramedia Pusat: Jakarta

[8] Jasfar, Farida. 2005. Manajemen Jasa: Pendekatan Terpadu. Jakarta: Ghalia Indonesia.

[9] Kandampully, J.A. 2007. Service Management: The New Paradigm in Hospitally. India: Pearson Education, Inc.

[10] Kasali, Rhenald. 2003. Management Public Relation \& Aplikasinya di Indonesia. Jakarta: PT Grafiti.

[11] Kotler, Philip. 2003. Marketing Management. New Jersey. Prentice - Hall Marketing.

[12] Kotler, Philip 2009. Marketing Management: Analysis, Planning, implementation and control, New Jersey, Prentice- International.

[13] Kotler, Philip, and Gary Armstrong, 2002. Principles of Marketing. Eleven Edition. New Jersey: Prentice- International.

[14] Kotler, Philip dan Keller, Kevin Lane. 2007. Manajemen Pemasaran. Jakarta: Ghalia Indonesia.

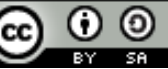


[15] Lukitasari, Lenni (2019). Pengaruh Bauran Pemasaran Jasa dan Kualitas Layanan Terhadap Kepuasan Mahasiswa Sekolah Tinggi Farmasi Bandung. Jurnal INTEKNA, Volume 19, No. 1, Mei 2019: 1 - 68

[16] Lupiyoadi, Rambat, dan Hamdani, A. 2008. Manajemen Pemasaran Jasa. Edisi Kedua. Jakarta: Salemba Empat.

[17] Payne, Adrian. 2014. Pemasaran Jasa; The Essence of Service Marketing. Yogyakarta: Andi.

[18] Ratih, Hurriyati. 2005. Bauran Pemasaran dan Loyalitas Konsumen. Bandung: Alfabeta.

[19] Sanusi, Anwar. 2011. Metodologi Penelitian Bisnis. Jakarta: Salemba Empat

[20] Soedijati, Elisabeth Koes 2011. Pengaruh Bauran Pemasaran Perguruan Tinggi terhadap Kepuasan dan Dampaknya Kepada Loyalitas Mahasiswa pada Tiga PTS terkemuka Di Kota Bandung. Jurnal Bina Ekonomi Majalah llmiah Fakultas Ekonomi Unpar Volume 15, Nomor 2, Agustus 2011
[21] Soemirat, Soleh. Ardianto, Elvinaro. 2007. Dasar-Dasar Public Relations. Bandung: PT Remaja Rosdakarya

[22] Sopiatin, Popi. 2010. Manajemen Belajar Berbasis Kepuasan Siswa. Bogor: Ghalia Indonesia

[23] Sugiyono. 2012. Metode Penelitian Kuantitatif Kualitatif dan R\&B. Bandung:Alfabet

[24] Swastha, Basu clan Irawan. 2006. Manajemen Pemasaran Modern. Liberty: Yogyakarta.

[25] Tjiptono, Fandy dan Anastasia Diana. 2000. Manajemen Jasa. Jogjakarta: Andi.

[26] . 2001. Total Quality Management. Yogyakarta: Andi.

[27] 2002. S'trategi Pemasaran. Yogyakarta: Andi.

[28] Zeithaml, V. A. and Bitner, M. J. 2013. Services Marketing: Integrating Customer Focus Across The Firm. McGraw-Hil

[29] Wijaya, David. (2012). Pemasaran Jasa Pendidikan. Jakarta: Salemba Empat 